University of Wollongong

Research Online

Australian Institute for Innovative Materials -

Papers

Australian Institute for Innovative Materials

$31-12-2014$

\title{
Ambient facile synthesis of gram-scale copper selenide nanostructures from commercial copper and selenium powder
}

Xinqi Chen

University of Wollongong, xc067@uowmail.edu.au

Zhen Li

University of Wollongong, zhenl@uow.edu.au

SX. Dou

University of Wollongong, shi@uow.edu.au

Follow this and additional works at: https://ro.uow.edu.au/aiimpapers

Part of the Engineering Commons, and the Physical Sciences and Mathematics Commons

Research Online is the open access institutional repository for the University of Wollongong. For further information contact the UOW Library: research-pubs@uow.edu.au 


\title{
Ambient facile synthesis of gram-scale copper selenide nanostructures from commercial copper and selenium powder
}

\author{
Abstract \\ Grams of copper selenides ( $\left.\mathrm{Cu}_{2-\mathrm{x}} \mathrm{Se}\right)$ were prepared from commercial copper and selenium powders in \\ the presence of thiol ligands by a one-pot reaction at room temperature. The resultant copper selenides \\ are a mixture of nanoparticles and their assembled nanosheets, and the thickness of nanosheets \\ assembled is strongly dependent on the ratio of thiol ligand to selenium powder. The resultant $\mathrm{Cu}_{2-\mathrm{x}} \mathrm{Se}(0$ \\ $\leq x \leq 0.25)$ nanostructures were treated with hydrazine solution to remove the surface ligands and then \\ explored as a potential thermoelectric candidate in comparison with commercial copper selenide \\ powders. The research provides a novel ambient approach for preparation of $\mathrm{Cu}_{2-\mathrm{x}} \mathrm{Se}$ nanocrystallines on \\ a large scale for various applications.

\section{Keywords} \\ synthesis, selenide, facile, powder, ambient, scale, nanostructures, copper, commercial, selenium, gram

\section{Disciplines} \\ Engineering | Physical Sciences and Mathematics

\section{Publication Details} \\ Chen, X., Li, Z. \& Dou, S. Xue. (2015). Ambient facile synthesis of gram-scale copper selenide \\ nanostructures from commercial copper and selenium powder. ACS Applied Materials and Interfaces, 7 \\ (24), 13295-13302.
}




\title{
Ambient facile synthesis of gram-scale copper
}

\section{selenide nanostructures from commercial copper and}

\section{selenium powder}

\author{
Xinqi Chen, ${ }^{\dagger, \S}$ Zhen $\mathrm{Li}^{\ddagger, \S^{*}}$ and Shi Xue Dou ${ }^{\S}$ \\ ${ }^{\dagger}$ Institute of Nanoscience and Nanotechnology, Department of Physics, Central China Normal \\ University, Wuhan, 430079, China. \\ ‡ School of Radiation Medicine and Radiation Protection, Collaborative Innovation Center of \\ Radiation Medicine of Jiangsu Higher Education Institutions, Soochow University, 199 Ren Ai \\ Road, Suzhou Industrial Park, Suzhou 215123, China. \\ $\S$ Institute for Superconducting and Electronic Materials, Squires Way, Innovation Campus of the \\ University of Wollongong, Wollongong, NSW 2500, Australia.
}


KEYWORDS Copper selenide, thermoelectric properties, semiconductor

ABSTRACT Grams of copper selenides $\left(\mathrm{Cu}_{2-\mathrm{x}} \mathrm{Se}\right)$ were prepared from commercial copper and selenium powders in the presence of thiol ligands by a one-pot reaction at room temperature. The resultant copper selenides are a mixture of nanoparticles and their assembled nanosheets, and the thickness of nanosheets assembled is strongly dependent on the ratio of thiol ligand to selenium powder. The resultant $\mathrm{Cu}_{2-x} \mathrm{Se}(0 \leq x \leq 0.25)$ nanostructures were treated with hydrazine solution to remove the surface ligands and then explored as a potential thermoelectric candidate in comparison with commercial copper selenide powders. The research provides a novel ambient approach for preparation of $\mathrm{Cu}_{2-x} \mathrm{Se}$ nano-crystallines in a large scale for various applications. 


\section{Introduction}

Transition metal chalcogenides have attracted considerable attention due to the wealth of physical and chemical properties that can be tuned through the careful manipulation of synthesis conditions. Copper selenides are typical transition metal chalcogenides with diverse applications ranging from energy conversion/storage to the biomedical regime, ${ }^{1-4}$ e.g., lithium-ion or sodiumion batteries, ${ }^{5,} 6$ electrocatalysis, ${ }^{7}$ quantum-dot-sensitized solar cells, ${ }^{8,} 9$ and photothermal therapy. ${ }^{10}$ Some of these applications require large amounts of samples for testing and measuring their performance, e.g., thermoelectric measurement requires gram-scale powders for sintering a small pellet, ${ }^{11,12}$ photovoltaic test needs tens of individual cells in a batch. ${ }^{13-17}$

In the thermoelectric regime, introduction of nanoscale structures into conventional thermoelectric bulk materials has been proven to be an effective way for improvement of thermoelectric performance. For example, non-doped $\beta$-phase $\mathrm{Cu}_{2} \mathrm{Se}$ and $\mathrm{Cu}_{2-x}$ Se fabricated by high-temperature solid state reaction have a figure of merit, $Z T$, of around 1.5 at $1000 \mathrm{~K},{ }^{18}$ which can be enhanced to $1.7-1.8$ at $700^{\circ} \mathrm{C}$ by the introduction of nanoscale precipitates through fast quenching of their liquids in the latest report. ${ }^{19}$ Although various strategies, such as hydrothermal or solvothermal approaches, ${ }^{20-30}$ sonochemistry, ${ }^{31,32}$ electrochemical-deposition, ${ }^{33-}$ 35 the microwave-assisted route, ${ }^{36}$ and the cation exchange method, ${ }^{37}$ have been developed to prepare nanoscale copper selenides, most methods are not able to produce large-scale samples for thermoelectric, photovoltaic, or other applications. For example, the yield of copper selenide nanomaterials prepared from hydrothermal or solvothermal approaches are limited by the volume, temperature, and pressure of Teflon-lined autoclaves, which make difficulties for scaleup preparation. Jiang et al prepared $\mathrm{Cu}_{2-\mathrm{x}} \mathrm{Se}$ nanostructures from $\mathrm{CuO}$ and Se powder in a mixture of ethylenediamine and hydrazine hydrate at room temperature. The use of expensive 
and corrosive mixed solvents leads to a high cost. ${ }^{38}$ Sonochemistry, electrochemical-deposition, and the microwave-assisted routes are energy-consuming and also face the difficulties in largescale preparation. For the ion exchange method, the replacement reactions between cations or anions are strongly relied on the size, morphology, and amount of nano-scaled precursors, and it couldn't be adopted for large-scale preparation. An alternative approach is the high-energy ballmilling method, ${ }^{12}$ which is energy-consuming and time-consuming. Thus, a facile synthesis of copper selenide on a large scale is desirable.

In this work, large amounts of $\mathrm{Cu}_{2-x} \mathrm{Se}$ nanostructures were synthesized through the ambient reaction of commercial copper powders with selenium powders in the presence of 2mercaptoethanol and traces of $\mathrm{NaOH}$. The as-prepared samples were treated with hydrazine solution to remove the adsorbed surface ligands. The resultant $\mathrm{Cu}_{2-x} \mathrm{Se}$ nanoparticles were sintered into pellets for investigation of their thermoelectric properties in comparison with commercial $\mathrm{Cu}_{2} \mathrm{Se}$ powder, which was sintered and measured under the same conditions. The obtained $Z T$ is comparable to that of the commercial samples and reaches 0.28 at $480^{\circ} \mathrm{C}$.

\section{Experimental section}

Chemical Reagents. Copper powder (-150 mesh, 99.5\%), 2-mercaptoethanol (> 99.0\%), hydrazine solution (35 wt\% in $\mathrm{H}_{2} \mathrm{O}$ ), and anhydrous ethanol (> 99.5\%) were purchased from Sigma-Aldrich and used as received. Sodium hydroxide (97.0\%) and selenium powder (-325 mesh, 99.5\%) were bought from Alfa Aesar.

Synthesis of $\mathbf{C u}_{2-x}$ Se nanostructures. Cu powder (0.06 mol), $12.6 \mathrm{~mL}$ 2-mercaptoethanol (0.18 mol), $1 \mathrm{~mL} \mathrm{NaOH} \mathrm{(7} \mathrm{M),} \mathrm{and} 100 \mathrm{~mL}$ anhydrous ethanol were loaded into a $250 \mathrm{~mL}$ glass flask. The mixture was stirred for $5 \mathrm{~min}$, and Se powder $(0.03 \mathrm{~mol})$ was added into the mixture. 
The color of the mixture gradually turned to black, suggesting the reaction of reddish copper with gray selenium powder. After the mixture was reacted for $24 \mathrm{~h}$ under gentle stirring, black precipitates were separated by centrifuge. These precipitates were dispersed in $20 \mathrm{~mL}$ hydrazine solution and stirred overnight. ${ }^{16}$ The precipitates were separated, washed with distilled water and ethanol several times, and then dried in vacuum at room temperature.

Characterization. X-ray diffraction (XRD) patterns for all samples were collected using $\mathrm{Cu}$ $\mathrm{K} \alpha$ radiation $(\lambda=1.5406 \AA)$ at $40 \mathrm{kV}$ and $25 \mathrm{~mA}$ at a scanning rate of $2^{\circ} \mathrm{min}^{-1}$ for $2 \theta$ in the range of 20-80 . Energy dispersive X-ray spectroscopy (EDS), X-ray photoelectron spectroscopy (XPS), inductively coupled plasma - atomic emission spectroscopy (ICP-AES), and Raman spectroscopy with a $10 \mathrm{~mW} \mathrm{He/Ne} \mathrm{laser} \mathrm{at} 632.8 \mathrm{~nm}$ (Jobin Yvon HR800) were used to characterize the chemical composition and crystal structure of the samples. The weight loss of the samples was measured with a Mettler-Toledo thermogravimetric analysis/differential scanning calorimetry (TGA/DSC) instrument from $50-900{ }^{\circ} \mathrm{C}$, with a heating rate of $5{ }^{\circ} \mathrm{C} \mathrm{min}^{-1}$ in argon. Field emission scanning electron microscope (FE-SEM) images of all the samples were collected using a JEOL JMS 7500-FA microscope with an accelerating voltage of $5 \mathrm{kV}$ and a secondary electron detector. The transmission electron microscope (TEM) images were collected on a JEOL ARM-200F microscope and a JEOL 2011 microscope operated at $200 \mathrm{kV}$.

Thermoelectric measurements. The hydrazine-treated copper selenide nanopowders were loaded into a graphite die with a diameter of $20 \mathrm{~mm}$ and sintered into a pellet at $430{ }^{\circ} \mathrm{C}$ under 65 MPa for 10 min by the spark plasma sintering (SPS) technique. The resultant pellet was cut into pieces and polished into parallelepipeds with dimensions of $\sim 2 \mathrm{~mm} \times 3 \mathrm{~mm} \times 10 \mathrm{~mm}$. The parallelepipeds were coated with a layer of boron nitride to protect the instrument against evaporation of the elements. ${ }^{39}$ The electrical conductivity and the Seebeck coefficient were 
measured simultaneously under helium atmosphere from room temperature to $480{ }^{\circ} \mathrm{C}$ using an Ozawa RZ2001i (Japan). A Linseis LFA1000 (Germany) instrument was used to determine the thermal diffusivity of samples that were cut and polished into a disk shape with a diameter of 10 mm and a thickness of $1 \mathrm{~mm}$. The thermal conductivity $(\kappa)$ was calculated using Equation (1):

$$
\kappa=D \times C_{p} \times \rho
$$

where $D$ is the thermal diffusivity, $C_{p}$ is the heat capacity, and $\rho$ is the density of the sample, which was calculated using the geometrical dimensions of the specimen and its mass. The heat capacity was determined using the differential scanning calorimetry (DSC) method.

\section{Results and discussion}

Copper selenide was fabricated from commercial copper powders and selenium powders in the presence of 2-mercaptoethanol at room temperature, and the resultant nanostructures were treated with hydrazine solution to remove surface organic material, which can influence the thermoelectric properties of pellets sintered from nanopowders due to the evaporation of organics during sintering and measurement at high temperature. Figure 1 shows FESEM and TEM images of the non-treated sample. A mixture of nanoparticles and their assembled nanosheets were observed [Figure 1(a-c)], in which the nanosheets have a thickness of around 7 nm (Figure S1 in Supporting Information). The selected-area electron diffraction (SAED) pattern in the inset of Figure 1(c) also indicates the polycrystalline nature of the products, which is consistent with the random orientation of the crystal lattice, as shown by the high-resolution TEM (HRTEM) image of the selected area [Figure 1(d)]. The sheet structure was destroyed after treatment with hydrazine solution due to the removal of ligands (Figure S2), which indicates that nanoparticles were assembled with the assistance of ligands. The HRTEM images of both non- 
treated and treated samples clearly display lattice fringes with a spacing of $0.33 \mathrm{~nm}$, matching well with the (111) planes of cubic $\mathrm{Cu}_{2-x} \mathrm{Se}$ [Figure 1(d), S2(c)]. These results suggest that removal of surface organic ligands by hydrazine did not influence the crystal structure. To confirm their crystal structures, XRD patterns of treated and non-treated samples were collected [Figure 2(a)]. All the peaks of both samples match well with standard peaks of face-centredcubic (fcc) $\mathrm{Cu}_{2} \mathrm{Se}$ (JCPDS 88-2043), demonstrating that no crystal structure or phase change occurred after treatment with hydrazine, although the morphology was drastically modified after treatment. The strong and sharp diffraction peaks suggest that both samples are well-crystallized, despite our room-temperature synthesis and modification. The average $\mathrm{Cu} / \mathrm{Se}$ ratios in nontreated and treated samples were determined to be 1.91 and 1.95 by ICP-AES.

To demonstrate the successful removal of surface organic material, TGA was used to compare the weight loss of samples before and after hydrazine treatment [Figure 2(b)]. The weight loss was reduced from $13 \%$ to only $3 \%$ after hydrazine treatment, which means that most of the surface ligands were removed. Raman spectroscopy was further applied to demonstrate the removal of surface ligands. The spectra of both the non-treated and the treated $\mathrm{Cu}_{2-x} \mathrm{Se}$ samples clearly show the characteristic vibration of the Cu-Se bond at $256 \mathrm{~cm}^{-1}$ (Figure S3). ${ }^{40-42}$ The spectra also confirm the absence of the typical peak of the $-\mathrm{SH}$ group at $2500-2600 \mathrm{~cm}^{-1} .{ }^{43}$ It is well known that $\mathrm{Cu}_{2-x} \mathrm{Se}$ is easy to oxidize, ${ }^{2,44}$ and XPS was used to determine the ratio of different valence states of $\mathrm{Cu}$ (i.e., $\mathrm{Cu}^{+} / \mathrm{Cu}^{2+}$ ) in both non-treated and treated $\mathrm{Cu}_{2-\gamma}$ Se samples (Figure 3). The XPS spectra of $\mathrm{Cu} 2 \mathrm{p}$ confirm the presence of both $\mathrm{Cu}^{+}$and $\mathrm{Cu}^{2+}$ in both samples [Figure 3(a, c)]. The ratio of $\mathrm{Cu}^{+} / \mathrm{Cu}^{2+}$ increases from 6.8 to 8.3 after the treatment with hydrazine due to the reduction capability of hydrazine. ${ }^{45-47}$ The spectra of Se 3d in both samples suggest the existence of $\mathrm{Se}^{2-}$ at $53.8 \mathrm{eV}$ [Figure 3(b, d)]. A small peak at $58.2 \mathrm{eV}$ in the original 
sample is attributed to the adsorbed organic selenide on its surface [Figure $3(\mathrm{~b}){ }^{2,48}$ which was successfully removed after treatment [Figure 3(d)].

Previous reports on the preparation of high crystalline metal chalcogenides, such as CuSe made from copper and selenium in pure 2-mercaptoethanol, ${ }^{49}$ and $\mathrm{Bi}_{2} \mathrm{~S}_{3}$ nanorods prepared from bismuth(III) monosalicylate in the presence of thioglycolic acid, demonstrates that the key role of - $\mathrm{SH}$ group is to provide $\mathrm{S}^{2-}$ or dissolve selenium to form highly reactive selenothiolate. ${ }^{50-53}$ Theoretical calculations show that the reaction between copper and reactive selenothiolate (e.g., $\mathrm{HOCH}_{2} \mathrm{CH}_{2} \mathrm{SSe}$ ) is spontaneous. ${ }^{54}$ The influence of 2-mercaptoethanol on the $\mathrm{Cu}_{2-x} \mathrm{Se}$ nanostructures was investigated (Figure 4). The ratio between $\mathrm{Cu}$ and 2-mercaptoethanol was varied from $1 / 3$, through $1 / 5,1 / 7,1 / 10,1 / 20$, and $1 / 30$, to $1 / 50$. The resultant nanostructures are nanosheets assembled from nanoparticles and their thickness increases with increasing concentration of 2-mercaptoethanol (Figure 4). The average thickness of the nanosheets obtained from the ratio of 1/3 is $7 \mathrm{~nm}$ (Figure S1), and it increases through $11 \mathrm{~nm}, 15 \mathrm{~nm}, 18 \mathrm{~nm}, 23 \mathrm{~nm}$, and $29 \mathrm{~nm}$, to $47 \mathrm{~nm}$ with the ratio of $\mathrm{Cu} / 2$-mercaptoethanol increasing from 1/3, through 1/5, $1 / 7,1 / 10,1 / 20$, and $1 / 30$, to $1 / 50$, respectively. These results demonstrate that more 2 mercaptoethanol promotes the growth of nanoparticles along the [111] direction, which is the automatically smooth surface with the lowest energy in the fcc structure. ${ }^{55}$ The XRD patterns of all the products (Figure S4) are matched well with fcc $\mathrm{Cu}_{2} \mathrm{Se}$ (JCPDS 88-2043), which means that the use of more 2-mercaptoethanol did not influence the crystal structure of $\mathrm{Cu}_{2-x} \mathrm{Se}$.

The evolution of the nanostructures was investigated in the case of the $\mathrm{Cu} / 2$-mercaptoethanol ratio of 1/50. The original commercial Cu powder is irregular and rough [Figure S5(a)]. 5 min after the addition of selenium powder into the reaction solution, small nanoparticles were formed and assembled into thin nanosheets with assistance of thiol ligands [Figure S5(b)]. Increasing the 
reaction time led to the growth of small nanoparticles and the assembling of nanoparticles [Figure S5(c-f)]. The XRD patterns of all the samples also confirm the evolution of the nanostructures and the transformation of $\mathrm{Cu}$ into $\mathrm{Cu}_{2-x} \mathrm{Se}$ (Figure S6). The product obtained within a short reaction time (i.e., $5 \mathrm{~min}$ ) is a mixture of $\mathrm{Cu}_{\text {and }} \mathrm{Cu}_{2-x} \mathrm{Se}$, as indicated by the high intensity of the $\mathrm{Cu}$ peaks and the very weak peaks from $\mathrm{Cu}_{2-x} \mathrm{Se}$ in its XRD pattern. Extended reaction time led to more $\mathrm{Cu}_{2-x} \mathrm{Se}$ being formed and an increase in the intensity of the $\mathrm{Cu}_{2-x} \mathrm{Se}$ peaks in the corresponding XRD patterns. The pure $\mathrm{Cu}_{2-\mathrm{x}} \mathrm{Se}$ obtained after $24 \mathrm{~h}$ reaction demonstrates the complete transformation of $\mathrm{Cu}$ into $\mathrm{Cu}_{2-x} \mathrm{Se}$.

An advantage of our method is that it is capable of producing grams of $\mathrm{Cu}_{2-x} \mathrm{Se}$ nanostructures in a one pot reaction for investigation of their properties and applications. As mentioned previously, copper selenides such as $\mathrm{Cu}_{2-x} \mathrm{Se}$ and $\mathrm{Cu}_{2} \mathrm{Se}$ could be candidate of thermoelectric materials. We investigate the thermoelectric properties of the as-synthesized $\mathrm{Cu}_{2-x} \mathrm{Se}$ nanostructures in comparison with commercial $\mathrm{Cu}_{2} \mathrm{Se}$ powder. Both synthetic and commercial powders were sintered by SPS, and the resultant pellets were cut into pieces of a similar size and then measured under the same conditions. ${ }^{56}$ As shown in Figure 5(a), the electrical conductivity of the synthetic $\mathrm{Cu}_{2-x} \mathrm{Se}$ sample is higher than that of the commercial $\mathrm{Cu}_{2} \mathrm{Se}$ powder from room temperature to $480{ }^{\circ} \mathrm{C}$. Due to its excellent electrical conductivity, the Seebeck coefficient of $\mathrm{Cu}_{2-x} \mathrm{Se}$ is lower than that of the commercial sample (i.e., $35 \mu \mathrm{V} / \mathrm{K}$ at room temperature and 80 $\mu \mathrm{V} / \mathrm{K}$ at $480{ }^{\circ} \mathrm{C}$ ) [Figure 5(b)]. Following the same trend as with the Seebeck coefficient, this sample has a power factor (PF) of $0.3 \mu \mathrm{W} \cdot \mathrm{cm}^{-1} \mathrm{~K}^{-2}$ at room temperature and $3.5 \mu \mathrm{W} \cdot \mathrm{cm}^{-1} \mathrm{~K}^{-2}$ at $480{ }^{\circ} \mathrm{C}$, lower than the corresponding values for the commercial sample [Figure 5(c)]. Heat capacities $\left(C_{p}\right)$ were measured and are shown in Figure 5(d). A sharp endothermal peak at around $140^{\circ} \mathrm{C}$ was observed in both the $\mathrm{Cu}_{2-x} \mathrm{Se}$ and the commercial samples. ${ }^{12}$ The overall thermal 
conductivity of the $\mathrm{Cu}_{2-x}$ Se and commercial samples calculated from Equation (1) demonstrates that our $\mathrm{Cu}_{2-x}$ Se sample has lower thermal conductivity than that of the commercial $\mathrm{Cu}_{2} \mathrm{Se}$ sample [Figure 5(e)]. The figures of merit for our $\mathrm{Cu}_{2-x} \mathrm{Se}$ and the commercial sample were calculated from Equation (2).

$$
Z T=\frac{s^{2} \sigma T}{\kappa}
$$

where $S, \sigma, \kappa$, and $T$ are the Seebeck coefficient, the electrical conductivity, the thermal conductivity, and the absolute temperature, respectively. The calculated $Z T$ values of the $\mathrm{Cu}_{2-x} \mathrm{Se}$ and $\mathrm{Cu}_{2}$ Se samples are plotted in Figure 5(f), where a slight decrease in $Z T$ at $140^{\circ} \mathrm{C}$ can be observed due to the presence of a sharp endothermal peak at this temperature [Figure 5(d)]. The $Z T$ values of our $\mathrm{Cu}_{2-x}$ Se and the commercial sample increase with increasing temperature, and reach 0.28 and 0.38 at $480^{\circ} \mathrm{C}$, respectively. These results are also similar to that for $\mathrm{Cu}_{2-x} \mathrm{Se}$ prepared from a high-temperature solid state reaction. ${ }^{57}$

The higher electrical conductivity and lower overall thermal conductivity of our $\mathrm{Cu}_{2-x} \mathrm{Se}$ sample could be attributed to its stable crystal structure, which was re-examined after SPS sintering and thermoelectric measurements. The XRD patterns show that there was no phase transition in the $\mathrm{Cu}_{2-x}$ Se sample after sintering and measurement at high temperature, except that the peaks became narrower and sharper due to the improvement in crystallization at high temperature [Figure 6(a)]. The original as-received commercial $\mathrm{Cu}_{2} \mathrm{Se}$ powder consists of cubic and orthorhombic phases, however, the fraction of orthorhombic $\mathrm{Cu}_{2}$ Se became pronounced after it was sintered into a pellet under the same conditions, and it was completely transformed into the orthorhombic structure after high-temperature measurements [Figure 6(b)]. The disordered $\mathrm{Cu}$ ions in the cubic structure at high temperature would be highly efficient phonon scattering 
centres as compared with the orthorhombic structure, which increase the carrier concentration. ${ }^{12}$, ${ }^{18}$ The average $\mathrm{Cu} / \mathrm{Se}$ ratios in pellets of our $\mathrm{Cu}_{2-x}$ Se and the commercial samples after SPS and measurement were determined to be 1.93 and 2.02, respectively, by ICP-AES, which shows a higher $\mathrm{Cu}$ deficiency in the $\mathrm{Cu}_{2-x}$ Se sample. Increased carrier concentration enhances the the electrical conductivity according to Equations (3-4), however, the Seebeck coefficient of the $\mathrm{Cu}_{2-\chi}$ Se compounds was found to decrease with increasing carrier concentration. ${ }^{57}$

$$
\begin{aligned}
& \rho=1 / \text { une } \\
& \alpha=\frac{k}{e}\left(r-\ln \frac{n}{N_{0}}\right)
\end{aligned}
$$

where $\rho, \mu, n, e, \alpha, k, r$, and $N_{0}$ are the electrical resistivity, carrier mobility, carrier concentration, charge of the electron, Seebeck coefficient, Boltzmann's constant, scattering factor, and Avogadro constant, respectively. ${ }^{58,59}$ In addition to the liquid-like behaviour of copper ions at high temperature, the lower thermal conductivity of our $\mathrm{Cu}_{2-x}$ Se sample could be also due to the presence of nanoscale grains, pores, and boundaries in the pellet, which can effectively improve the phonon scattering and decrease the thermal conductivity. SEM images of pellets made from $\mathrm{Cu}_{2-x} \mathrm{Se}$ nanoparticles and commercial $\mathrm{Cu}_{2} \mathrm{Se}$ powder in Figure 6(c-d) clearly show that the $\mathrm{Cu}_{2-\chi}$ Se pellet has a larger amount of nanoscale particles and pores than the $\mathrm{Cu}_{2} \mathrm{Se}$ pellet, although they were sintered under the same conditions (i.e., $430^{\circ} \mathrm{C}, 65 \mathrm{MPa}$, and $10 \mathrm{~min}$ ) by SPS technology. In addition, the pronounced $\mathrm{Cu}$-deficiency in the $\mathrm{Cu}_{2-x}$ Se sample leads to more vacancies, which are also responsible for its lower thermal conductivity.

\section{Conclusions}


Grams of $\mathrm{Cu}_{2-x} \mathrm{Se}$ nanostructures have been synthesized by a one-pot reaction of commercial copper powder with Se powder in the presence of 2-mercaptoethanol. The resultant nanostructures were treated with hydrazine solution to remove adsorbed surface ligands. The hydrazine treatment destroyed the sheet-like structure, and resulted in pristine $\mathrm{Cu}_{2-x} \mathrm{Se}$ nanoparticles, which were sintered into a pellet. Their thermoelectric properties were measured in comparison with commercial $\mathrm{Cu}_{2} \mathrm{Se}$ powder under the same conditions. Their thermoelectric properties show that the $\mathrm{Cu}_{2-\gamma}$ Se sample has a similar temperature-dependent $Z T\left(0.28\right.$ at $\left.480^{\circ} \mathrm{C}\right)$ to that of the commercial sample. The $\mathrm{Cu}_{2-x} \mathrm{Se}$ sample retained the same crystal structure and morphology after SPS sintering and thermoelectric measurements at high temperature. Our research provides a simple way to prepare large-scale copper selenide nanostructures for diverse applications. 


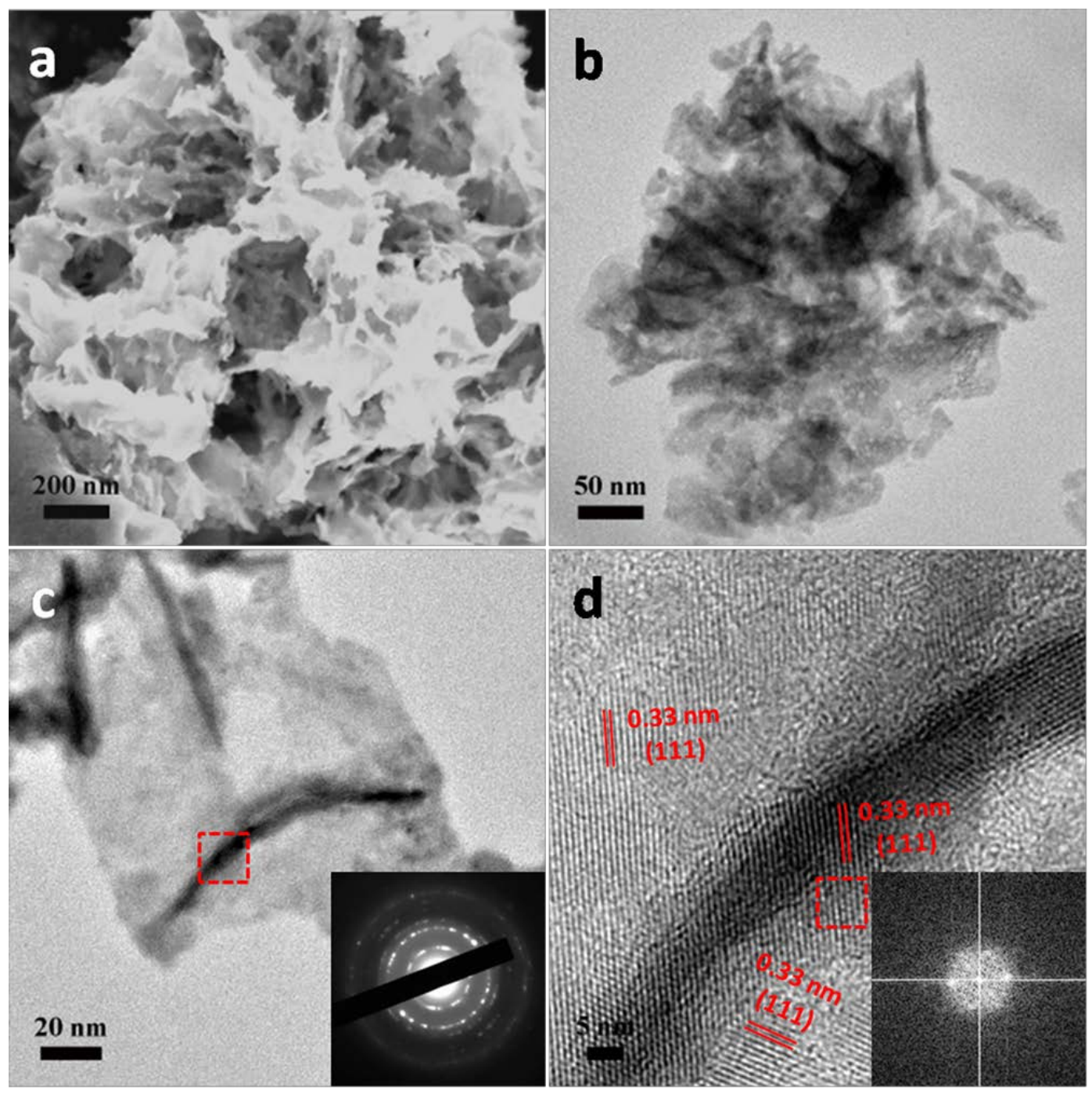

Figure 1. (a-c) FESEM and TEM images of as-prepared $\mathrm{Cu}_{2-x}$ Se nanostructures. The inset in (c) is the SAED pattern of a typical single layer of $\mathrm{Cu}_{2-x}$ Se. (d) HRTEM image of the selected area in (c), with the inset of FFT pattern from the area selected with the dashed square in (d). 

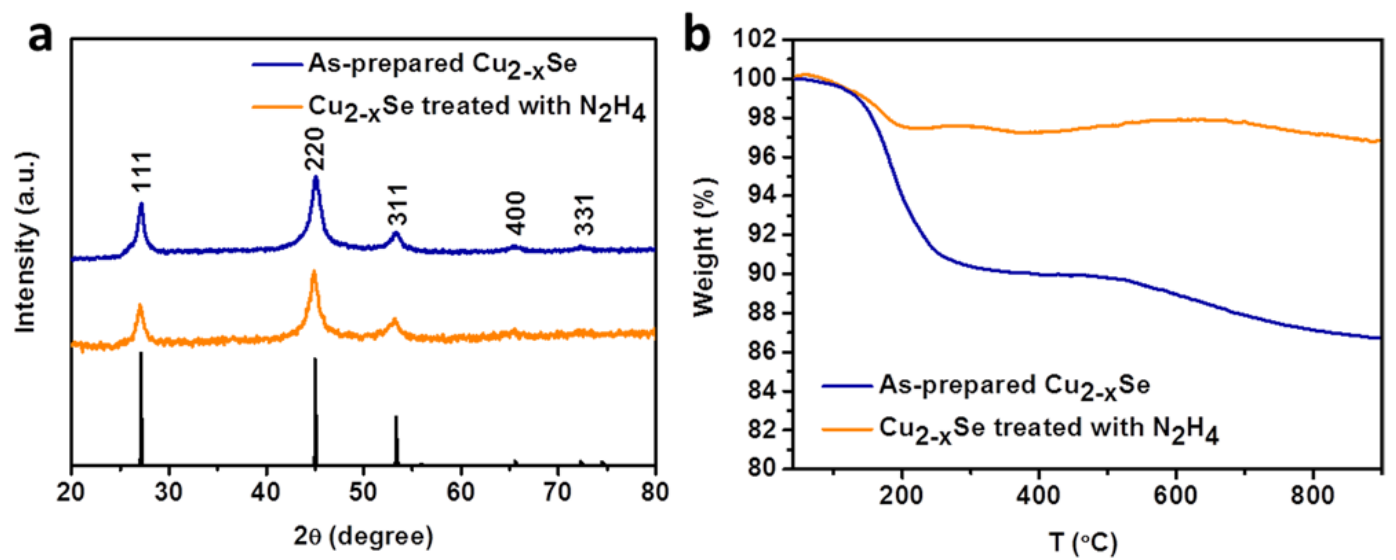

Figure 2. (a) XRD patterns and (b) TGA curves of as-prepared $\mathrm{Cu}_{2-x}$ Se nanostructures before and after treatment with $\mathrm{N}_{2} \mathrm{H}_{4}$. The vertical lines in (a) mark the line positions of the $\mathrm{Cu}_{2} \mathrm{Se}$ standard (JCPDS 88-2043). 


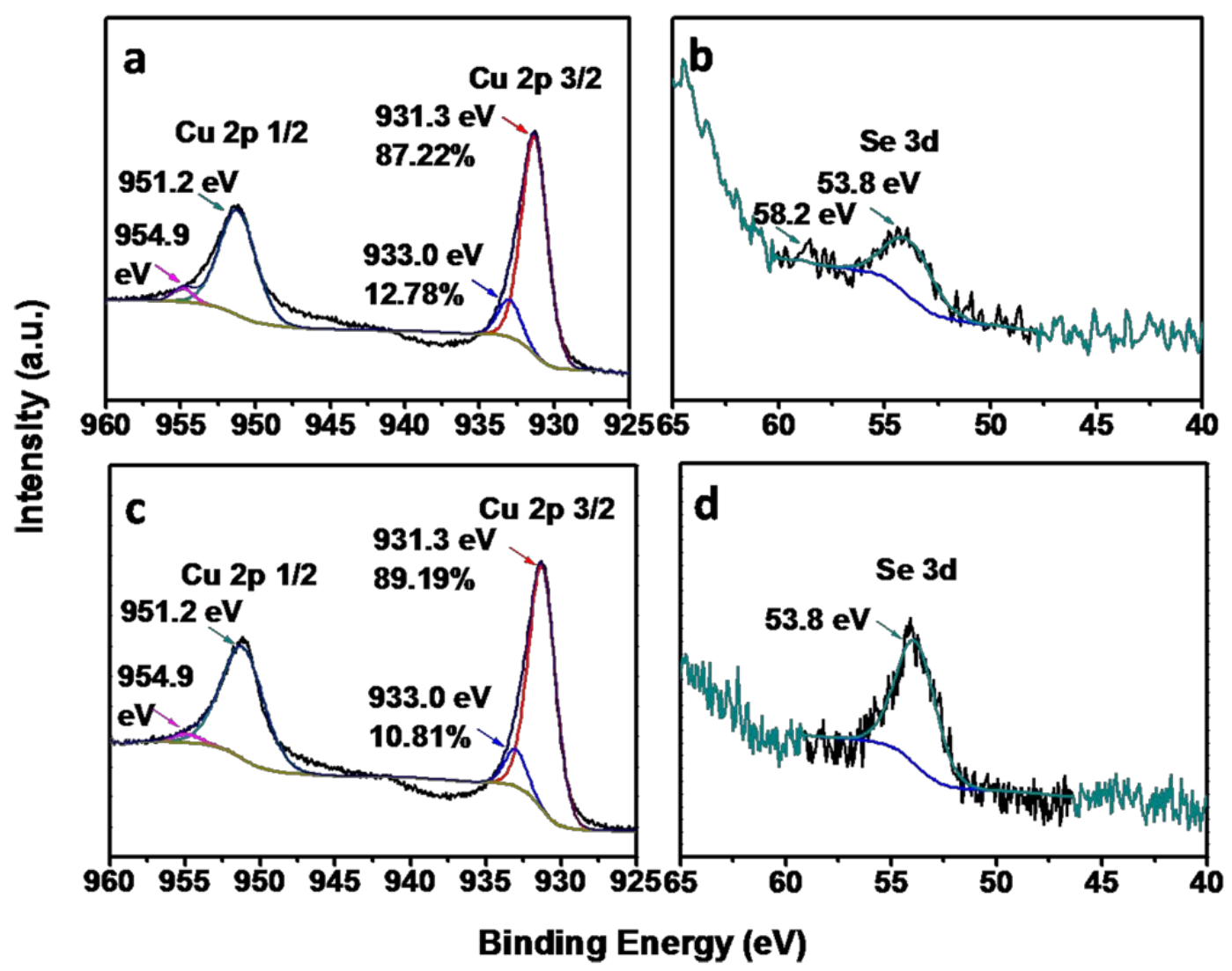

Figure 3. XPS spectra of (a) Cu 2p and (b) Se 3d of as-prepared $\mathrm{Cu}_{2-x} \mathrm{Se}$; (c) $\mathrm{Cu} 2 \mathrm{p}$ and (d) Se 3d of $\mathrm{Cu}_{2-x}$ Se powder treated with $\mathrm{N}_{2} \mathrm{H}_{4}$. 


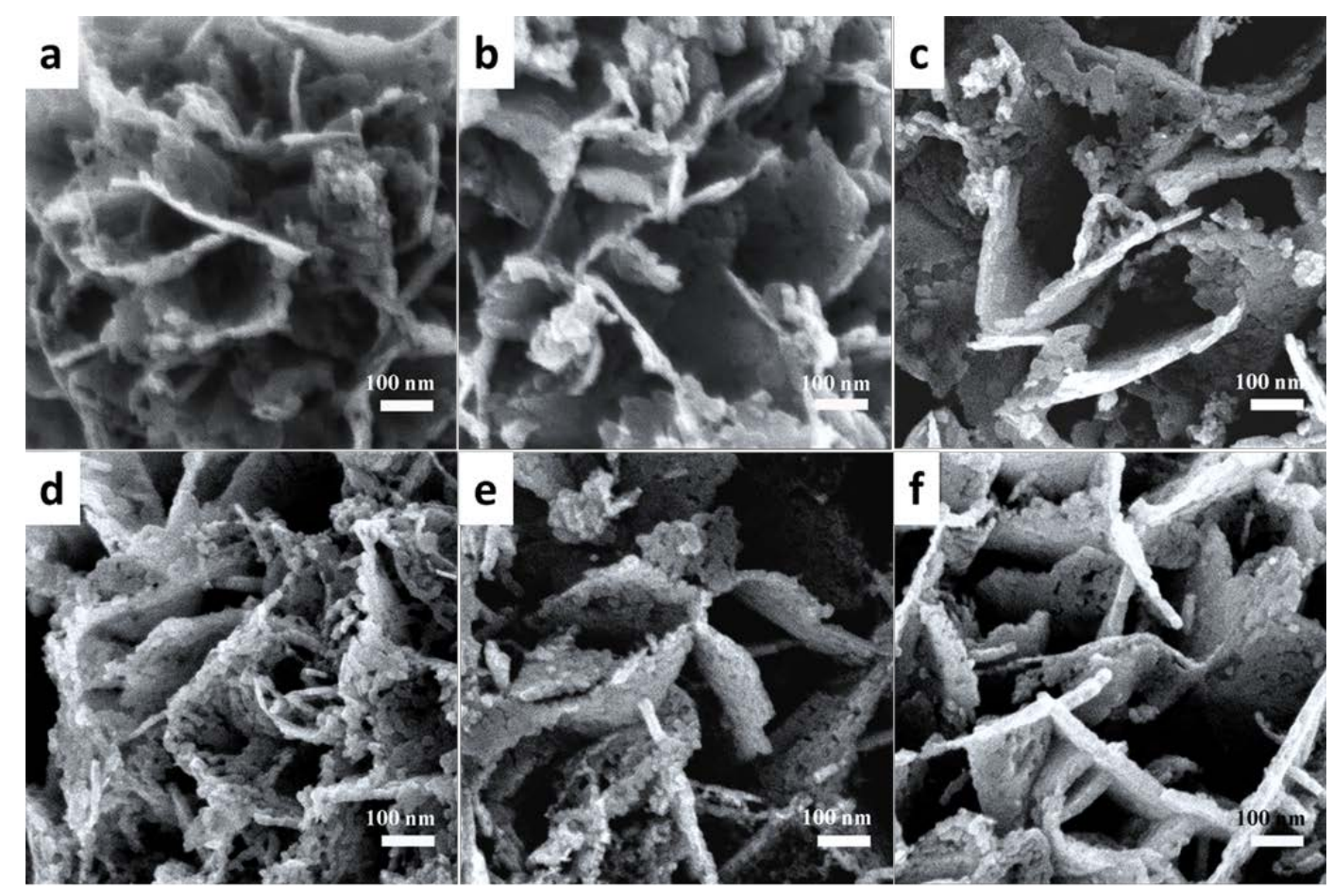

Figure 4. SEM images of $\mathrm{Cu}_{2-x} \mathrm{Se}$ nanostructures prepared from different molar ratios of $\mathrm{Cu}$ to 2 mercaptoethanol: (a) $1 / 5$, (b) $1 / 7$, (c) $1 / 10$, (d) $1 / 20$, (e) $1 / 30$, (f) $1 / 50$. 

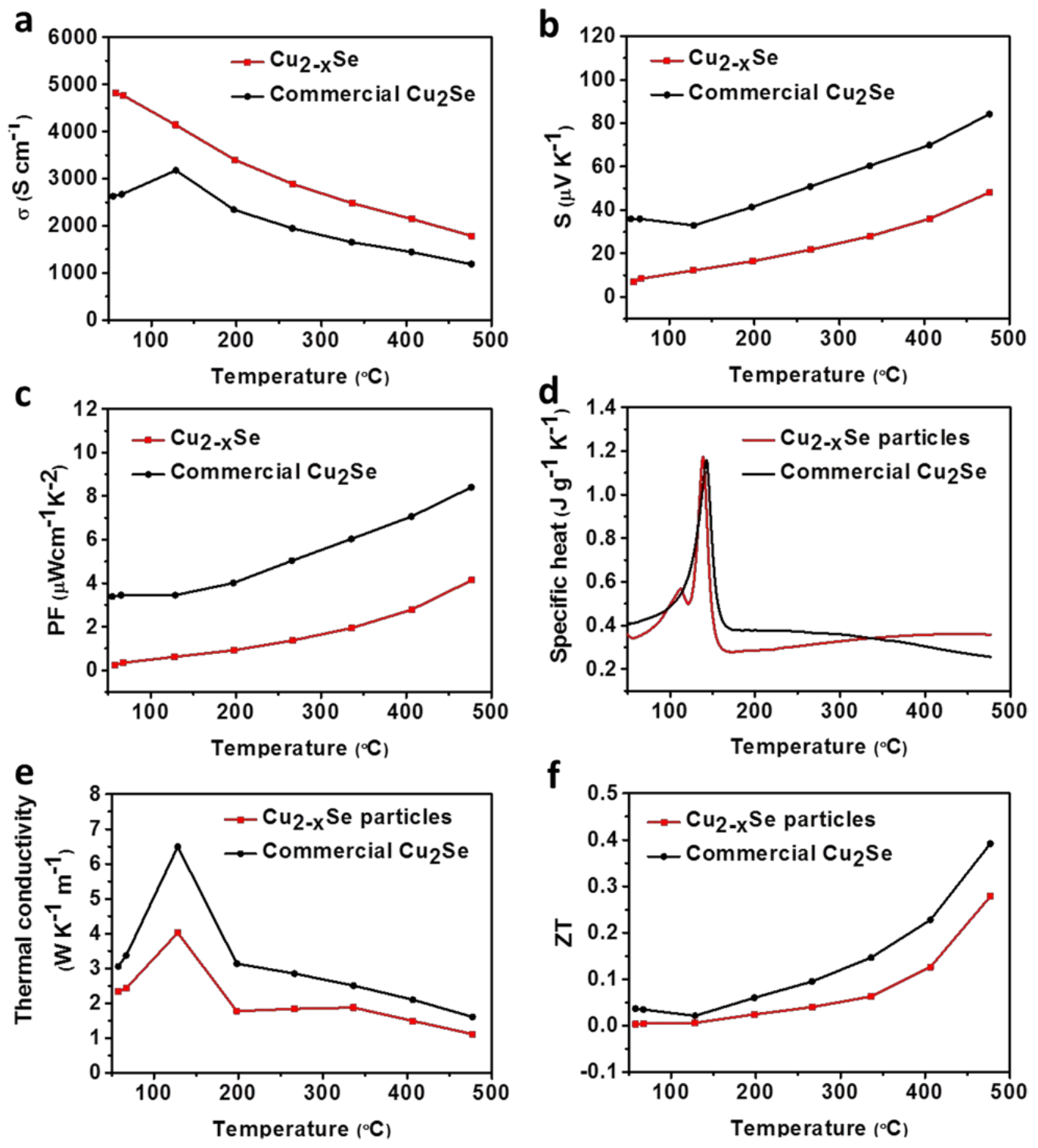

Figure 5. Temperature dependence of the thermoelectric properties of synthetic $\mathrm{Cu}_{2-x} \mathrm{Se}$ and commercial $\mathrm{Cu}_{2} \mathrm{Se}$ samples: (a) electrical conductivity; (b) Seebeck coefficient; (c) power factor; (d) specific heat capacity $\left(C_{p}\right)$; (e) thermal conductivity; (f) figure-of merit calculated using Equation (2). 

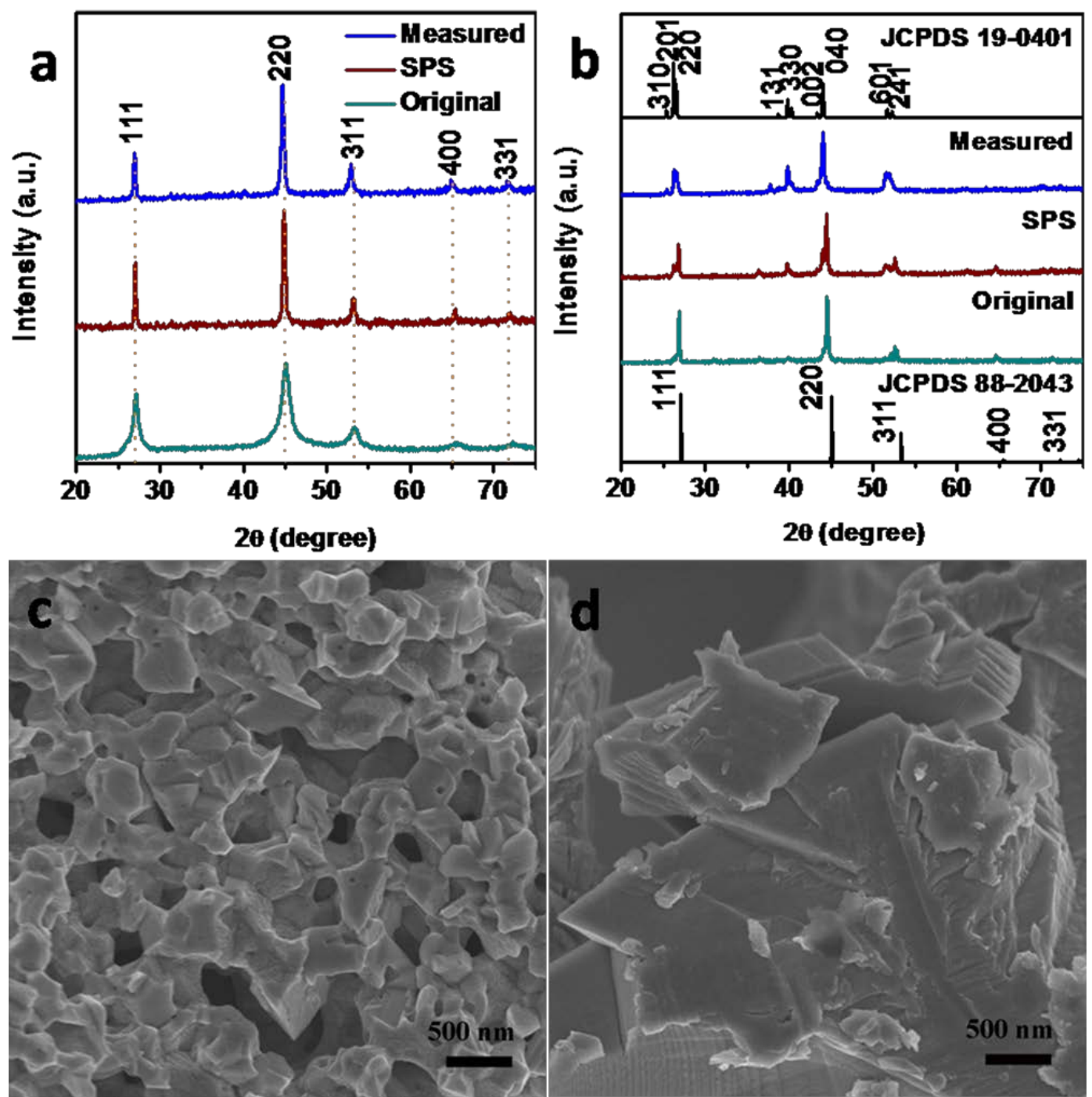

Figure 6. $\mathrm{XRD}$ patterns of (a) as-prepared $\mathrm{Cu}_{2-x}$ Se nanopowder (Original), $\mathrm{Cu}_{2-x}$ Se pellet after sintering at $430^{\circ} \mathrm{C}$ under $65 \mathrm{MPa}$ (SPS), and $\mathrm{Cu}_{2-x}$ Se pellet after thermoelectric measurements (Measured); (b) commercial $\mathrm{Cu}_{2} \mathrm{Se}$ powder, $\mathrm{Cu}_{2}$ Se pellet sintered under the same conditions as in (a), and $\mathrm{Cu}_{2}$ Se pellet after thermoelectric measurements. FESEM images of cross-sections of (c) $\mathrm{Cu}_{2-x} \mathrm{Se}$ and (d) $\mathrm{Cu}_{2} \mathrm{Se}$ pellets after sintering at $430^{\circ} \mathrm{C}$ under $65 \mathrm{MPa}$ by the spark plasma sintering technique and thermoelectric measurements. 


\section{ASSOCIATED CONTENT}

Supporting Information. FESEM and TEM images of samples treated with $\mathrm{N}_{2} \mathrm{H}_{4}$; Raman spectra of samples; XRD patterns of samples at different ratios of $\mathrm{Cu} / 2$-mecaptoethanol and different reaction times; FESEM images of samples after different reaction times. This material is available free of charge via the Internet at http://pubs.acs.org.

\section{AUTHOR INFORMATION}

\section{Corresponding Author}

* Z. Li (email: zhenl@uow.edu.au; zhenli@suda.edu.cn); Tel: +61-2-42215163; Fax: +61-242215731.

\section{Author Contributions}

Xin Qi Chen did the experiments, characterized samples, and wrote the manuscript; Zhen Li supervised students in doing experiments and revised the manuscript; and Shi Xue Dou assisted in writing the manuscript.

\section{ACKNOWLEDGMENTS}

X. Chen gratefully acknowledges funding from the Chinese Scholarship Council (CSC) (201206770014). Z. Li acknowledges support from the Australian Research Council (ARC) through the Discovery Projects DP130102699 and DP130102274. S. Dou is grateful for support from the Baosteel-Australia Research Centre (BARC) through the project BA110011 and to the ARC through the Linkage Project LP120200289. The authors also appreciate support from the Electron Microscopy Centre at UOW (Linkage Infrastructure, Equipment and Facility Grant 
LE120100104 for JEOL JEM-ARM200F), and thank Dr. Tania Silver for critical reading of the manuscript.

\section{REFERENCES}

(1) Zhao, Y. X.; Burda, C. Development of Plasmonic Semiconductor Nanomaterials with Copper Chalcogenides for A Future with Sustainable Energy Materials. Energy Environ. Sci. 2012, 5, 5564-5576.

(2) Riha, S. C.; Johnson, D. C.; Prieto, A. L. $\mathrm{Cu}_{2} \mathrm{Se}$ Nanoparticles with Tunable Electronic Properties Due to a Controlled Solid-State Phase Transition Driven by Copper Oxidation and Cationic Conduction. J. Am. Chem. Soc. 2011, 133, 1383-1390.

(3) Kriegel, I.; Jiang, C. Y.; Rodriguez, J.; Schaller, R. D.; Talapin, D. V.; Como, E.;

Feldmann, J. Tuning the Excitonic and Plasmonic Properties of Copper Chalcogenide Nanocrystals. J. Am. Chem. Soc. 2012, 134, 1583-1590.

(4) Kriegel, I.; Rodriguez, J.; Wisnet, A.; Zhang, H.; Waurisch, C.; Eychmuller, A.; Dubavik, A.; Govorov, A. O.; Feldmann, J. Shedding Light on Vacancy-Doped Copper Chalcogenides: Shape-Controlled Synthesis, Optical Properties, and Modeling of Copper Telluride Nanocrystals with Near-Infrared Plasmon Resonances. ACS Nano 2013, 7, 4367-4377.

(5) Xue, M. Z.; Zhou, Y. N.; Zhang, B.; Yu, L.; Zhang, H.; Fu, Z. W. Fabrication and Electrochemical Characterization of Copper Selenide Thin Films by Pulsed Laser Deposition. $J$. Electrochem. Soc. 2006, 153, A2262-A2268.

(6) Yue, J. L.; Sun, Q.; Fu, Z. W. $\mathrm{Cu}_{2} \mathrm{Se}$ with Facile Synthesis as A Cathode Material for Rechargeable Sodium Batteries. Chem. Commun. 2013, 49, 5868-5870.

(7) Liu, S. L.; Zhang, Z. S.; Bao, J. C.; Lan, Y. Q.; Tu, W. W.; Han, M.; Dai, Z. H. Controllable Synthesis of Tetragonal and Cubic Phase $\mathrm{Cu}_{2} \mathrm{Se}$ Nanowires Assembled by Small 
Nanocubes and Their Electrocatalytic Performance for Oxygen Reduction Reaction. J. Phys. Chem. C 2013, 117, 15164-15173.

(8) Bo, F.; Zhang, C. F.; Wang, C. L.; Xu, S. H.; Wang, Z. Y.; Cui, Y. P. From Red Selenium to Cuprous Selenide: A Novel and Facile Route to A High Performance Metal Selenide Cathode for Sensitized Solar Cells. J. Mater. Chem. A 2014, 2, 14585-14592.

(9) Choi, H. M.; Ji, I. A.; Bang, J. H. Metal Selenides as a New Class of Electrocatalysts for Quantum Dot-Sensitized Solar Cells: A Tale of $\mathrm{Cu}_{1.8} \mathrm{Se}$ and PbSe. ACS Appl. Mater. Interfaces 2014, 6, 2333-2341.

(10) Hessel, C. M.; Pattani, V. P.; Rasch, M.; Panthani, M. G.; Koo, B.; Tunnell, J. W.; Korgel, B. A. Copper Selenide Nanocrystals for Photothermal Therapy. Nano Lett. 2011, 11, 2560-2566.

(11) Han, C.; Li, Z.; Dou, S. X. Recent Progress in Thermoelectric Materials. Chin. Sci. Bull. 2014, 59, 2073-2091.

(12) Yu, B.; Liu, W. S.; Chen, S.; Wang, H.; Wang, H. Z.; Chen, G.; Ren, Z. F. Thermoelectric Properties of Copper Selenide with Ordered Selenium Layer and Disordered Copper Layer. Nano Energy 2012, 1, 472-478.

(13) Amiri, O.; Salavati-Niasari, M.; Sabet, M.; Ghanbari, D. Synthesis and Characterization of $\mathrm{CuInS}_{2}$ Microsphere under Controlled Reaction Conditions and its Application in Low-Cost Solar Cells. Mater. Sci. Semicond. Process. 2013, 16, 1485-1494.

(14) Amiri, O.; Salavati-Niasari, M.; Sabet, M.; Ghanbari, D. Sonochemical Method for Preparation of Copper Indium Sulfide Nanoparticles and their Application for Solar Cell. Comb. Chem. High Throughput Screening 2014, 17, 183-189.

(15) Amiri, O.; Salavati-Niasari, M.; Farangi, M.; Mazaheri, M.; Bagheri, S. Stable 
Plasmonic-Improved Dye Sensitized Solar Cells by Silver Nanoparticles Between Titanium Dioxide Layers. Electrochim. Acta 2015, 152, 101-107.

(16) Amiri, O.; Salavati-Niasari, M.; Farangi, M. Enhancement of Dye-Sensitized Solar Cells Performance by Core Shell Ag@Organic (Organic = 2-nitroaniline, PVA, 4-choloroaniline and PVP): Effects of Shell Type on Photocurrent. Electrochim. Acta 2015, 153, 90-96.

(17) Amiri, O.; Salavati-Niasari, M.; Rafiei, A.; Farangi, M. 147\% Improved Efficiency of Dye Synthesized Solar Cells by Using CdS QDs, Au Nanorods and Au Nanoparticles. RSC Adv. 2014, 4, 62356-62361.

(18) Liu, H. L.; Shi, X.; Xu, F. F.; Zhang, L. L.; Zhang, W. Q.; Chen, L. D.; Li, Q.; Uher, C.; Day, T.; Snyder, G. J. Copper Ion Liquid-Like Thermoelectrics. Nat. Mater. 2012, 11, 422-425.

(19) Zhao, L. L.; Wang, X. L.; Wang, J. Y.; Cheng, Z. X.; Dou, S. X.; Wang, J. L.; Liu, L. Q. Superior Intrinsic Thermoelectric Performance with ZT of 1.8 in Single-Crystal and MeltQuenched Highly Dense $\mathrm{Cu}_{2-\mathrm{x}} \mathrm{Se}$ Bulks. Scientific Reports 2015, 5, 7671(1-6).

(20) Zhang, Y.; Hu, C. G.; Zheng, C. H.; Xi, Y.; Wan, B. Y. Synthesis and Thermoelectric Property of $\mathrm{Cu}_{2-x}$ Se Nanowires. J. Phys. Chem. C 2010, 114, 14849-14853.

(21) Li, D. P.; Zheng, Z.; Lei, Y.; Ge, S. X.; Zhang, Y. D.; Zhang, Y. G.; Wong, K. W.; Yang, F. L.; Lau, W. M. Design and Growth of Dendritic $\mathrm{Cu}_{2-\mathrm{x}} \mathrm{Se}$ and Bunchy CuSe Hierarchical Crystalline Aggregations. CrystEngComm 2010, 12, 1856-1861.

(22) Deka, S.; Genovese, A.; Zhang, Y.; Miszta, K.; Bertoni, G.; Krahne, R.; Giannini, C.; Manna, L. Phosphine-Free Synthesis of p-Type Copper(I) Selenide Nanocrystals in Hot Coordinating Solvents. J. Am. Chem. Soc. 2010, 132, 8912-8914.

(23) Hsiang, H. I.; Hsu, W. H.; Lu, L. H.; Chang, Y. L.; Yen, F. S. Cuprous Selenide NanoCrystal Synthesis and Characterization. Mater. Res. Bull. 2013, 48, 715-720. 
(24) Filippo, E.; Manno, D.; Serra, A. Synthesis and Growth Mechanism of Dendritic $\mathrm{Cu}_{2-\mathrm{x}} \mathrm{Se}$ Microstructures. J. Alloys Compd. 2012, 538, 8-10.

(25) Mi, L. W.; Li, Z.; Chen, W. H.; Ding, Q.; Chen, Y. F.; Zhang, Y. D.; Guo, S. S.; Jia, H. M.; He, W. W.; Zheng, Z. 3D $\mathrm{Cu}_{2-\mathrm{x}} \mathrm{Se}$ Nano/Micropeony Architectures: Large-Scale Solvothermal Synthesis, Characterization, and Catalytic Properties. Thin Solid Films 2013, 534, 22-27.

(26) Su, H. L.; Xie, Y.; Qiao, Z. P.; Qian, Y. T. Formation of $\mathrm{Cu}_{2-x} \mathrm{Se}(\mathrm{en})_{2}$ in a Solvothermal Process and Conversion to Nanocrystalline $\mathrm{Cu}_{2-\mathrm{x}}$ Se. Mater. Res. Bull. 2000, 35, 1129-1135.

(27) Kumar, P.; Singh, K.; Srivastava, O. N. Template Free-Solvothermaly Synthesized Copper Selenide (CuSe, $\mathrm{Cu}_{2-\mathrm{x}} \mathrm{Se}$, beta- $\mathrm{Cu}_{2} \mathrm{Se}$ and $\mathrm{Cu}_{2} \mathrm{Se}$ ) Hexagonal Nanoplates from Different Precursors at Low Temperature. J. Cryst. Growth 2010, 312, 2804-2813.

(28) Liu, Y. F.; Cao, J. B.; Li, C.; Zeng, J. H.; Tang, K. B.; Qian, Y. T.; Zhang, W. Q. Hydrazine Route to One-Dimensional Structural Metal Selenides Crystals. J. Cryst. Growth 2004, 261, 508-513.

(29) Han, Z. H.; Li, Y. P.; Zhao, H. Q.; Yu, S. H.; Yin, X. L.; Qian, Y. T. A Simple Solvothermal Route to Copper Chalcogenides. Mater. Lett. 2000, 44, 366-369.

(30) Liu, Y. F.; Zeng, J. H.; Li, C.; Cao, J. B.; Wang, Y. Y.; Qian, Y. T. Formation of Semiconductor $\mathrm{Cu}_{2-\mathrm{x}}$ Se Rod-Like Crystals Through a Solvothermal Reaction. Mater. Res. Bull. 2002, 37, 2509-2516.

(31) Xie, Y.; Zheng, X. W.; Jiang, X. C.; Lu, J.; Zhu, L. Y. Sonochemical Synthesis and Mechanistic Study of Copper Selenides $\mathrm{Cu}_{2-\mathrm{x}} \mathrm{Se}$, beta-CuSe, and $\mathrm{Cu}_{3} \mathrm{Se}_{2}$. Inorg. Chem. 2002, 41, 387-392.

(32) Xu, S.; Wang, H.; Zhu, J. J.; Chen, H. Y. Sonochemical Synthesis of Copper Selenides 
Nanocrystals with Different Phases. J. Cryst. Growth 2002, 234, 263-266.

(33) Thouin, L.; Rouquette-sanchez, S.; Vedel, J. Electrodeposition of Copper Selenium Binaries in a Citric-Acid Medium. Electrochim Acta 1993, 38, 2387-2394.

(34) Massaccesi, S.; Sanchez, S.; Vedel, J. Cathodic Deposition of Copper Selenide Films on Tin Oxide in Sulfate-Solutions. J. Electrochem. Soc. 1993, 140, 2540-2546.

(35) Yu, R.; Ren, T.; Sun, K. J.; Feng, Z. C.; Li, G. N.; Li, C. Shape-Controlled Copper Selenide Nanocubes Synthesized by an Electrochemical Crystallization Method. J. Phys. Chem. C 2009, 113, 10833-10837.

(36) Cao, X. B.; Zhao, C.; Lan, X. M.; Gao, G. J.; Qian, W. H.; Guo, Y. MicrowaveEnhanced Synthesis of $\mathrm{Cu}_{3} \mathrm{Se}_{2}$ Nanoplates and Assembly of Photovoltaic CdTe- $\mathrm{Cu}_{3} \mathrm{Se}_{2}$ Clusters. J. Phys. Chem. C 2007, 111, 6658-6662.

(37) Li, H. B.; Zanella, M.; Genovese, A.; Povia, M.; Falqui, A.; Giannini, C.; Manna, L. Sequential Cation Exchange in Nanocrystals: Preservation of Crystal Phase and Formation of Metastable Phases. Nano Lett. 2011, 11, 4964-4970.

(38) Jiang, Y.; Xie, B.; Wu, J.; Yuan, S. W.; Wu, Y.; Huang, H.; Qian, Y. T. RoomTemperature Synthesis of Copper and Silver, Nanocrystalline Chalcogenides in Mixed Solvents. J. Solid State Chem. 2002, 167, 28-33.

(39) Han, C.; Sun, Q.; Cheng, Z. X.; Wang, J. L.; Li, Z.; Lu, G. Q.; Dou, S. X. Ambient Scalable Synthesis of Surfactant-Free Thermoelectric CuAgSe Nanoparticles with Reversible Metallic-n-p Conductivity Transition. J. Am. Chem. Soc. 2014, 136, 17626-17633.

(40) Cho, A.; Ahn, S.; Yun, J. H.; Gwak, J.; Ahn, S. K.; Shin, K.; Yoo, J.; Song, H.; Yoon, K. The Growth of $\mathrm{Cu}_{2-x}$ Se Thin Films Using Nanoparticles. Thin Solid Films 2013, 546, 299-307.

(41) Witte, W.; Kniese, R.; Powalla, M. Raman Investigations of $\mathrm{Cu}(\mathrm{In}, \mathrm{Ga}) \mathrm{Se}_{2}$ Thin Films 
with Various Copper Contents. Thin Solid Films 2008, 517, 867-869.

(42) Izquierdo-Roca, V.; Saucedo, E.; Ruiz, C. M.; Fontane, X.; Calvo-Barrio, L.; AlvarezGarcia, J.; Grand, P. P.; Jaime-Ferrer, J. S.; Perez-Rodriguez, A.; Morante, J. R.; Bermudez, V. Raman Scattering and Structural Analysis of Electrodeposited CuInSe 2 and S-rich Quaternary CuIn(S,Se) 2 Semiconductors for Solar Cells. Phys. Status Solidi A 2009, 206, 1001-1004.

(43) Szafranski, C. A.; Tanner, W.; Laibinis, P. E.; Garrell, R. L. Surface-Enhanced Raman Spectroscopy of Aromatic Thiols and Disulfides on Gold Electrodes. Langmuir 1998, 14, 35703579.

(44) Miszta, K.; Brescia, R.; Prato, M.; Bertoni, G.; Marras, S.; Xie, Y.; Ghosh, S.; Kim, M. R.; Manna, L. Hollow and Concave Nanoparticles via Preferential Oxidation of the Core in Colloidal Core/Shell Nanocrystals. J. Am. Chem. Soc. 2014, 136, 9061-9069.

(45) Chang, Y.; Lye, M. L.; Zeng, H. C. Large-Scale Synthesis of High-Quality Ultralong Copper Nanowires. Langmuir 2005, 21, 3746-3748.

(46) Xiong, J. Y.; Li, Z.; Chen, J.; Zhang, S. Q.; Wang, L. Z.; Dou, S. X. Facile Synthesis of Highly Efficient One-Dimensional Plasmonic Photocatalysts through Ag@ $\mathrm{Cu}_{2} \mathrm{O}$ Core-Shell Heteronanowires. ACS Appl. Mater. Interfaces 2014, 6, 15716-15725.

(47) Han, C.; Li, Z.; Li, W. J.; Chou, S. L.; Shi, X. D. Controlled Synthesis of Copper Telleride Nanostructures for Long-cycling Anode in Lithium Ion Batteries. J. Mater. Chem. A 2014, 2, 11683-11690.

(48) Fonder, G.; Volcke, C.; Csoka, B.; Delhalle, J.; Mekhalif, Z. Electrochemical and Spectroscopic Study of $\mathrm{C}_{12} \mathrm{H}_{25} \mathrm{X}$ Molecules Adsorption on Copper Sheets, X (-SH, -S-S-, -SeH and -Se-Se-). Electrochim. Acta 2010, 55, 1557-1567.

(49) Kumar, P.; Gusain, M.; Nagarajan, R. Solvent-Mediated Room Temperature Synthesis of 
Highly Crystalline $\mathrm{Cu}_{9} \mathrm{~S}_{5}\left(\mathrm{Cu}_{1.8} \mathrm{~S}\right)$, CuSe, $\mathrm{PbS}$, and PbSe from Their Elements. Inorg. Chem. 2012, 51, 7945-7947.

(50) Amaratunga, W.; Milne, J. Studies on the Interaction of Selenite and Selenium with Sulfur Donors. Part 2. A Kinetic-Study of the Reaction with 2-Mercaptoethanol. Can. J. Chem. 1994, 72, 2506-2515.

(51) Afsar, H.; Tor, I.; Apak, R. Reduction of Selenium(IV) and Complexation of Selenium(0) with 2-Mercaptoethanol. Analyst 1989, 114, 1315-1318.

(52) Afsar, H.; Apak, R.; Tor, I. Spectrophotometric Determination of Selenium with 2Mercaptoethanol. Analyst 1989, 114, 1319-1321.

(53) Salavati-Niasari, M.; Behfard, Z.; Amiri, O.; Khosravifard, E.; Hosseinpour-Mashkani, S. M. Hydrothermal Synthesis of Bismuth Sulfide $\left(\mathrm{Bi}_{2} \mathrm{~S}_{3}\right)$ Nanorods: Bismuth(III) Monosalicylate Precursor in the Presence of Thioglycolic Acid. J. Cluster Sci. 2013, 24, 349363.

(54) Chen, X. Q.; Li, Z.; Bai, Y.; Sun, Q.; Wang, L. Z.; Dou, S. X. Room-Temperature Synthesis of $\mathrm{Cu}_{2-\mathrm{x}} \mathrm{E}(\mathrm{E}=\mathrm{S}$, Se) Nanotubes with Hierarchical Architecture as High-Performance Counter Electrodes of Quantum-Dot-Sensitized Solar Cells. Chem. Eur. J. 2014, 21, 1055-1063.

(55) Tan, M.; Chen, X. Q. Growth Mechanism of Single Crystal Nanowires of fcc Metals (Ag, Cu, Ni) and hcp Metal (Co) Electrodeposited. J. Electrochem. Soc. 2012, 159, K15-K20.

(56) Chen, X. Q.; Li, Z.; Yang, J. P.; Sun, Q.; Dou, S. X. Aqueous Preparation of SurfactantFree Copper Selenide Nanowires. J. Colloid Interface Sci. 2014, 442, 140-146.

(57) Xiao, X. X.; Xie, W. J.; Tang, X. F.; Zhang, Q. J. Phase Transition and High Temperature Thermoelectric Properties of Copper Selenide $\mathrm{Cu}_{2-\mathrm{x}} \mathrm{Se}(0<=\mathrm{x}<=0.25)$. Chin. Phys. $B$ 2011, 20, 0872019(1-8). 
(58) Ge, Z. H.; Zhang, B. P.; Yu, Z. X.; Li, J. F. Effect of Spark Plasma Sintering Temperature on Thermoelectric Properties of $\mathrm{Bi}_{2} \mathrm{~S}_{3}$ Polycrystal. J. Mater. Res. 2011, 26, 2711-2718.

(59) Liu, W. S.; Zhang, B. P.; Li, J. F.; Zhang, H. L.; Zhao, L. D. Enhanced Thermoelectric Properties in $\mathrm{CoSb}_{3-\mathrm{x}} \mathrm{Te}_{\mathrm{x}}$ Alloys Prepared by Mechanical Alloying and Spark Plasma Sintering. $J$. Appl. Phys. 2007, 102, 103717. 
Insert Table of Contents Graphic and Synopsis Here

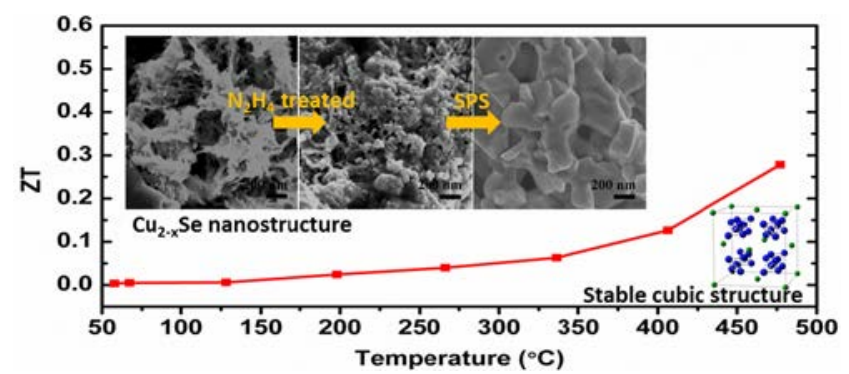

Grams of $\mathrm{Cu}_{2-x}$ Se nanostructures have been synthesized by a one-pot reaction of commercial copper powder with Se powder in the presence of 2-mercaptoethanol, and treated with hydrazine solution to remove adsorbed surface ligands. The resultant $\mathrm{Cu}_{2-x}$ Se nanostructures were sintered into pellets to show similar temperature-dependent figure of merit $\left(Z T=0.28\right.$ at $\left.480^{\circ} \mathrm{C}\right)$ to that of the commercial sample. 